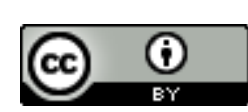

\title{
INTERTEXTUALIDADE EM FREIRE: PEDAGOGIA DA ESPERANÇA AO ENCONTRO DA PEDAGOGIA DO OPRIMIDO, CONTINUIDADES E PENSAMENTO NOVO
}

\begin{abstract}
INTERTEXTUALITY IN FREIRE:
PEDAGOGY OF HOPE MEETS THE PEDAGOGY OF

THE OPPRESSED, CONTINUITIES AND NEW THOUGHTS

INTERTEXTUALIDAD EN FREIRE:

PEDAGOGÍA DE LA ESPERANZA AL ENCUENTRO DE

LA PEDAGOGÍA DEL OPRIMIDO, CONTINUIDADES Y PENSAMIENTO NUEVO

Eunice Macedo ${ }^{1}$

Alexandra Carvalho ${ }^{2}$

RESUMO: Entendendo que, como experiência humana, a existência de Freire consiste no entretecer de uma diversidade de textos, não podemos reduzir esses textos a meros eventos biográficos. Ocorrendo em contexto, os textos de Freire dialogam com textos de outros e com os seus textos, aos quais se reportam das mais diversas formas, inclusivamente a partir de críticas que lhe foram feitas, sendo geradores de novos significados. Não sendo intertextualidade um conceito utilizado por Freire, parece-nos uma lente adequada para referir os diferentes textos e intertextos que emergem na relação entre a Pedagogia da esperança e a Pedagogia do oprimido, o que permite aprofundar a incorporação da experiência-na-obra e da obra-na-experiência, numa perspectiva ontológica. São estas dimensões de intertextualidade que exploramos nesta aproximação à obra de Freire, num eixo de continuidades e pensamento novo entre estas duas Pedagogias.
\end{abstract}

PALAVRAS-CHAVE: Paulo Freire. Intertextualidade. Pedagogia.

ABSTRACT: Understanding that Freire's existence as a human experience consists of the interweaving of a diversity of texts, we cannot reduce these texts to mere biographical events. Taking place in context, the texts of Freire dialogue with texts of others and with his own texts, to which they report to on the most diverse forms, including the criticisms that have been made to them. Hence these texts become generators of new meanings. Even if intertextuality is not a concept used by Freire, it seems an adequate lens to refer the different texts and inter-texts that emerge in the relation between the Pedagogy of hope and the Pedagogy of the oppressed, which allows to deepen the incorporation of the experience-in-work and of work-in-experience, from an ontological perspective. It is these dimensions of intertextuality that we explore in this approach to Freire's work, in an axis of continuities and new thinking between these two Pedagogies.

KEYWORDS: Paulo Freire. Intertextuality. Pedagogy.

RESUMEN: Entendiendo que, como experiencia humana, la existencia de Freire consiste en el entretejer de una diversidad de textos, no podemos reducir esos textos a meros acontecimientos biográficos. Producidos en contexto, los textos de Freire dialogan con textos de otros y con sus textos, a los que se remiten de las más diversas formas, incluso a partir de críticas que le fueron hechas, siendo generadores de nuevos significados. No siendo intertextualidad un concepto utilizado por Freire, nos parece una lente adecuada para referir los diferentes textos e inter-textos que emergen en la relación entre la Pedagogía de la esperanza y la Pedagogía del

\footnotetext{
${ }^{1}$ Submetido em: 10/01/2019 - Aceito em: 14/01/2019 - Publicado em: 17/01/2019
}

\begin{tabular}{l|c|c|c|c|c|c} 
(C) Rev. Educ. Perspec. & Viçosa, $M G$ & v.9 & n.3 & p.564-575 & set./dez. 2018 & eISSN 2178-8359 \\
\hline
\end{tabular}


oprimido, lo que permite profundizar la incorporación de la experiencia en la obra y de la obra en la experiencia, en una perspectiva ontológica. Son estas dimensiones de intertextualidad que exploramos en esta aproximación a la obra de Freire, en un eje de continuidades y pensamiento nuevo entre estas dos Pedagogías.

PALABRAS CLAVE: Freire. Intertextualidad. Pedagogía.

\section{INTERTEXTUALIDADE EM FREIRE}

Como seres históricos, como 'seres para si', autobiográficos, sua transformação, que é desenvolvimento, se dá no tempo que é seu, nunca fora dele (FREIRE, 2000, p. 159 , grifo do original).

A expressão "intertextualidade", é usada neste artigo na medida em que permite enfatizar o hibridismo e a pluralidade de escritos produzidos por Freire. Não se pode deixar de relevar a relação dialógica que se estabelece entre diferentes vozes e subjetividades na produção dos textos que se tecem antes e para lá das palavras impressas na Pedagogia da esperança e o intuito consciente de produção de uma cultura humanizada e humanizante, transformadora. Assim, esta noção de intertextualidade permite desvelar e aprofundar os sentidos da produção escrita de Freire bem como a lógica crítica e reflexiva em que se enraízam os seus conceitos. Pode, pois, argumentar-se da existência de uma forte articulação entre as propostas freirianas e aquilo que o próprio autor designa por temas geradores, referidos a uma época particular. Como refere Romão (2000), "mais do que lições teóricas" aprendemos com Paulo Freire "a razão ontológica da esperança e os fundamentos histórico-sociais da existência libertadora"iii .

A presente acentuação da intertextualidade em Freire inspira-se na análise da obra de Simone de Beauvoir, no livro "Simone de Beauvoir: conflits d'une intellectuelle" (MOI, 1995). Encontramos paralelos conceituais na leitura que se pode fazer da intertextualidade nestes dois autores, na medida em que tanto Freire como Beauvoir iii incorporam e simbolizam muitos dos conflitos intelectuais e políticos do seu tempo. Pode dizer-se que uma visão holística da obra de Freire permite também uma compreensão mais abrangente das tensões políticas e sociais da sua época, que se prolongam além do seu tempo de vida e que são reconfiguradas no atual momento político tanto no Brasil como um pouco por todo o mundo. Vários trabalhos articulam a vida e a obra de Freire (CORTESÃO, 2003; GADOTTI, 1996a, 2001; GUTIERREZ, 2008; MACEDO et al., 2013; MACEDO, 2017; SOUZA, 2001; TORRES, 1997). Essa intertextualidade é acentuada pelo próprio Paulo Freire, particularmente com a elaboração da Pedagogia da esperança, uma obra com a qual, de certa forma, 'justifica', reflete e legitima a construção da Pedagogia do oprimido, inserindo-a num momento particular da sua vida. Como acentua José Eustáquio Romão na introdução a este dossiê temático, será de notar que Freire escreve a "Pedagogia do oprimido" a partir de um lugar de opressão, enquanto exilado no Chile. Já a escrita da Pedagogia da esperança surge a partir de um lugar de libertação e de "opção pela vida" (ABRAMOWICZ, 1996, p. 203), após a criação do Instituo Paulo Freire, em 1991, e o reinvestimento na vida afetiva e familiar.

\begin{tabular}{l|l|l|l|l|l|l} 
() Rev. Educ. Perspec. & Viçosa, $M G$ & v.9 & n.3 & p.564-575 & set./dez. 2018 & eISSN 2178-8359 \\
\hline
\end{tabular}


Será interessante ainda notar que a "Pedagogia do oprimido" e a "Pedagogia da esperança" apresentam diferenças tanto no estilo da escrita como no tipo de recursos utilizados pelo autor, já que no primeiro texto a argumentação se suporta num conjunto amplo de referências teóricas, enquanto o segundo assume um caráter mais autobiográfico-narrativo.

Dando força à tese da intertextualidade vida-obra em Freire, nas primeiras palavras de introdução à Pedagogia da esperança, o autor considera nela três momentos distintos. $\mathrm{O}$ primeiro faz uma recuperação do seu percurso de vida, desde a infância à adultez e ao anúncio da "Pedagogia do oprimido", que passa da construção oral à escrita; e o segundo discute aspetos particulares da "Pedagogia do oprimido", procedendo também à análise de críticas que lhe foram feitas, na década de 1970. Já no último momento, Freire revive e repensa aspetos singulares da sua "andarilhagem pelos quatro cantos do mundo a que [...] [foi] levado pela Pedagogia do oprimido" (FREIRE, 1994, p. 13), recusando uma perspectiva saudosista "de quem fala do que já foi" e afirmando a atualidade das reflexões aí produzidas - o "que está sendo". O autor traça também os objetivos da obra, como texto que se vai constituindo por relação com a retoma da experiência:

\begin{abstract}
Minha preocupação, neste trabalho esperançoso [...] vem sendo mostrar, excitando, desafiando a memória, como se estivesse escavando o tempo, o processo mesmo como minha reflexão, meu pensamento pedagógico, sua elaboração, de que o livro é um momento, vem se constituindo. Como vem se constituindo meu pensamento pedagógico, inclusive nesta Pedagogia da esperança, em que discuto a esperança com que escrevi a Pedagogia do oprimido (FREIRE, 1994, p. 65).
\end{abstract}

Por sua vez, Miguel Escobar Guerrero (2007, p. 25), que se debruça naquilo que designa "as quatro etapas de Paulo Freire nas suas cinco pedagogias: do oprimido, da esperança, da autonomia, da indignação e da tolerância,"iv , permite também acentuar a intertextualidade entre as Pedagogias do oprimido e da esperança, pois a primeira é:

\footnotetext{
um canto ao amor, um desafio ao desejo de romper as cadeias da opressão, uma crença feita luta na capacidade do ser humano para opor a biofilia (Eros) à necrofilia (Tánatos) e empreender o caminho da sua libertação, assumindo o compromisso da sua humanização [...] mediatizados pelo mundo da nossa história e da nossa cultura (GUERRERO, 2007, p. 28).
}

Já a "Pedagogia da esperança", como obra que, conforme Guerrero, conclui a etapa de vida de Freire, entre 1980 e 1992, insere-se no estímulo à luta pela humanização, à resistência face ao fatalismo, à implicação na construção de sonhos e utopias. Nesse quadro, num tempo de consolidação do capitalismo, em que os índices de perversão e de violência são acentuados e a desesperança se instala, Freire escreve a Pedagogia da esperança para reforçar que a esperança se constrói na luta e que investindo no sonho de humanização poderá ampliar os espaços da luta por uma sociedade reinventada de baixo para cima. 
Na nossa perspectiva, é no quadro de preocupações com "situações-limite" de opressão e com os atos-limite que as vêm endereçar, que Freire reflete, na "Pedagogia da esperança", sobre o processo de escrita da "Pedagogia do oprimido". Parece poder inferir-se que a própria construção do livro se estruturou em torno de temas geradores de época, que emergiram do seu quotidiano. É a estes que Freire dedica um tempo de reflexão, em termos da sua sequência temática e dos desafios que estes suscitam, num encadeamento de construção reflexiva. Parece ser nesta medida que o autor afirma:

envolvendo a gestação das idéias, [a construção do livro] envolve também o momento ou os momentos da ação em que se foram gerando e os de pô-las no papel. Na verdade, as idéias que precisam de ser defendidas, que implicam outras idéias, que são reditas em "esquinas" várias dos textos a que os autores e autoras se sentem obrigados a voltar de vez em quando vão se gestando ao longo de sua prática na prática social maior de que fazem parte (FREIRE, 1994, p. 53).

Num enquadramento ontológico, que temos vindo a referir, importa acentuar que Freire identifica como "temas geradores" de época aqueles que se referem aos seres humanos como um todo. Como explicitava já na "Pedagogia do oprimido", inserindo-se em unidades epocais mais amplas, os temas geradores abarcam também um conjunto de unidades e subunidades de caráter continental, regional, nacional e a outros níveis, que podem ser representados numa relação concêntrica do global para o particular. Tendo conotações dinâmicas, estes temas desafiam ao cumprimento de tarefas particulares, que são assumidas de forma conflitual por grupos com interesses distintos. Ao tempo da escrita de Freire, este assume como fundamental o tema da libertação e o seu contrário, o tema da dominação (FREIRE, 2000).

Estes temas geradores - que parecem informar a construção e a escrita das suas obras instalam e legitimam formas de pensamento-linguagem referidas a uma realidade, como textos constituintes do "universo temático" de cada época particular (FREIRE, 2000). Ao incluir diversas formas de conflito e de legitimação de relações entre oprimidos e opressores, cada universo temático pode também conduzir à emersão de formas de resistência, numa relação dialética entre esses temas e os seus opostos (por exemplo, libertação/dominação, como citado acima). Estas formas de resistência - corporizadas em "atos-limite" - vêm endereçar "situações-limite' instituintes de processos de desumanização, muitas vezes encobertas e naturalizadas como "determinante histórico", no interior de "amarras reais" de tipo social, económico, político e ideológico.

A escrita da "Pedagogia do oprimido" parece então poder constituir um "ato-limite" com que Freire enfrenta, com esperança, a "situação-limite" em que ele próprio estava inserido como exilado. Situação que admite ser difícil enfrentar, mas que também reclama a necessidade de analisar criticamente com vista a uma "compreensão mais histórica", que invista na ideia de transformação e possibilidade. Sendo o exílio um contexto de "injustiça, exploração, opressão e violência", é a partir da posição de exilado, potenciadora de opressão, que Freire assume o

\begin{tabular}{l|l|l|l|l|l|l} 
(C) Rev. Educ. Perspec. & Viçosa, $M G$ & v.9 & n.3 & p.564-575 & set./dez. 2018 & eISSN 2178-8359 \\
\hline
\end{tabular}


compromisso com a libertação, afirmando o "anseio de liberdade, de justiça, de luta dos oprimidos pela recuperação de sua humanidade roubada" (FREIRE, 2000, p. 30). Como é profundamente elucidado na "Pedagogia da esperança", com a escrita da "Pedagogia do oprimido", Freire envolve-se na recuperação da sua vocação ontológica para ser mais. Tendo a escrita ocorrido no interior daquilo que o autor designou por "contexto de empréstimo" onde se experimentou no exílio, projetando-se para o seu "contexto original”. Afirma:

Não poderia re-pensar a Pedagogia do oprimido, sem pensar, sem lembrar alguns dos lugares onde a escrevi, mas sobretudo, um deles, a casa onde vivi tempo feliz, e de onde parti do Chile, carregando saudades, sofrido por partir, mas esperançoso de poder responder aos desafios que esperavam por mim (FREIRE, 2000, p. 61-62).

Retomando a tese da intertextualidade patente nos diálogos que antecedem a escrita freiriana, no que diz respeito às "andarilhagens" de Freire, destacamos memórias, retomadas na "Pedagogia da esperança", relativas à sua visita a Portugal. Freire recupera com a sua ida a Coimbra a reflexão sobre o processo de alfabetização desenvolvido por mulheres do GRAAL, dando destaque a Maria de Lourdes Pintasilgo ${ }^{v}$ e a Teresa Santa Clara. Num tempo que antecipou a Revolução dos Cravos, que em Portugal derruba o regime autoritário e instaura um regime democrático, em 25 de abril de 1974, Freire recupera factos que antecederam essa revolução, para valorizar, o posterior "discurso afetivo que expressava o mútuo agradecimento. O deles a mim. O meu a eles e a elas” (FREIRE, 1994, p. 177). O gesto de rebeldia de uma camponesa idosa, recentemente alfabetizada, é expressão disso, já que ela recolhe a propaganda fascista, mobilizando o povo de uma aldeia na recusa a "apoiar a manifestação direitista" (FREIRE, 1994, p. 177). Nesse âmbito Freire acentua:

Não foi preciso fazer-se discursos sobre a luta de classes, que, na verdade, existe, durante o curso de alfabetização para que ela e seus companheiros, na hora certa, percebessem a relação entre a leitura da palavra, a leitura do mundo e sobretudo a transformação do mundo [...] (FREIRE, 1994, p. 177).

Há um conjunto de tópicos e preocupações da "Pedagogia do oprimido" que norteiam a "Pedagogia da esperança" a qual, por sua vez, assenta na experiência humana de Freire em diálogo com outras pessoas (e textos), como temos vindo a enfatizar, para enriquecer o contributo da "Pedagogia do oprimido" com experiências a diversas vozes, que acentuam o valor do saber popular:

Minhas longas conversas com pescadores em suas caiçaras na praia de Pontas de Pedra, em Pernambuco, como meus diálogos com camponeses e trabalhadores urbanos, nos córregos e morros do Recife, não apenas me familiarizaram com sua linguagem mas também me aguçaram a sensibilidade à boniteza com que sempre falam de si, até de suas dores, e do mundo. Boniteza e segurança também (FREIRE, 1994, p. 69).

Será importante realçar também que, na "Pedagogia da esperança", Freire assume as diversas interpretações da "Pedagogia do oprimido" por estudantes de países periféricos, que enfatizam os seus aspectos políticos, filosóficos, éticos, ideológicos e epistemológicos, bem

\begin{tabular}{l|c|c|c|c|c|c|} 
() Rev. Educ. Perspec. & Viçosa, $M G$ & v.9 & n.3 & p.564-575 & set./dez. 2018 & eISSN 2178-8359 \\
\hline
\end{tabular}


como por trabalhadores imigrantes europeus (italianos, espanhóis, portugueses) que compreendiam a obra como instrumento para melhorar a sua prática futura. Analisa também como estudantes universitários buscavam teorizar a prática e como os operários tentavam articular a teoria com o que realizavam na sua prática.

O enquadramento intertextual, é ainda revelado na análise e resposta de Freire a algumas críticas à "Pedagogia do oprimido", na década de 1970. Destacamos, as críticas feministas ao uso de uma linguagem sexista, que o autor admite e revê, através de maior vigilância na escrita, situando homens e mulheres como responsáveis pelo processo de engajamento social (MACEDO; CARVALHO, 2017), e fazendo a afirmação de si como feminista (MACEDO, 2017). Argumenta que o sexismo da linguagem vai além da dimensão gramatical para constituir uma questão ideológica:

Em certo momento de minhas tentativas, puramente ideológicas, de justificar a mim mesmo, a linguagem machista que usava, percebi a mentira ou a ocultação da verdade que havia na afirmação: 'Quando falo homem a mulher necessariamente está incluída'. E por que os homens não se acham incluídos quando dizemos: 'As mulheres estão decididas a mudar o mundo'? (FREIRE, 1994, p. 67).

Na mesma linha afirma ainda em entrevista, "a linguagem não apenas veicula o saber, mas é saber. Ela é produção de saber” (FREIRE apud FREIRE, 2001, p. 213).

$\mathrm{Na}$ "Pedagogia da esperança", Paulo Freire reflete também acerca da crítica à sua linguagem rebuscada, dita muitas vezes elitista e de difícil compreensão para os oprimidos, como leitores da obra. Lamenta também algumas críticas feitas à "Pedagogia do oprimido" que, na sua perspectiva, resultam de desconhecimento e/ou de falta de aprofundamento. Referimos concretamente a crítica, que recusa, aos conceitos de oprimido e de povo.

Face ao que foi dito, assume-se a impossibilidade teórico-metodológica de separar os textosda-vida e os textos-dos-textos de Freire, os quais não podem ser lidos apenas em si mesmos, já que isso impediria a revelação de mesclas e conexões potencialmente significativas e estruturantes. Paulo Freire surge como recurso "intertextual" constituído pelo modo como as suas experiências de vida se refletem na sua obra e como esta se reflete nas primeiras. É este olhar que alimenta, neste artigo, a busca de relações entre continuidades e a emersão de um pensamento novo na "Pedagogia da esperança".

\section{ENTRE CONTINUIDADES E UM PENSAMENTO NOVO}

De forma coerente com a práxis freiriana, a "Pedagogia da esperança" é marcada por uma implicação forte na inovação criativa e em processos emancipatórios. José Eustáquio Romão acentua a retomada da "Pedagogia do oprimido" na "Pedagogia da esperança", afirmando a

\begin{tabular}{l|c|c|c|c|c|c} 
(C) Rev. Educ. Perspec. & Viçosa, $M G$ & v.9 & n.3 & p.564-575 & set./dez. 2018 & eISSN 2178-8359 \\
\hline
\end{tabular}


vocação ontológica do oprimido na marcha para a humanização, como condição e manifestação do processo civilizatório:

\begin{abstract}
A "Pedagogia da esperança" é uma retomada da "Pedagogia do oprimido", porque, conforme [Freire] aí demonstrara, somente por meio da ação do oprimido é possível a libertação e, portanto, a retomada da esperança, porque somente ele pode reiniciar a marcha para o humanismo e para a civilização (ROMÃO, 2008, p. 17).
\end{abstract}

Por sua vez, Gadotti, na obra "Paulo Freire: Uma Biobibliografia" (1996b), congrega textos que abordam a vida, a obra e/ou o legado de Freire. Referindo-se à "Pedagogia da esperança", o autor afirma o seu caráter de resistência e de utopia de construção de uma sociedade outra, como "imperativo existencial histórico":

Contra essa corrente neoliberal e anti-humanista, Paulo Freire retoma com vigor, nesse livro, a utopia e mostra a trajetória de um punhado de pessoas que não perderam a esperança na construção de uma sociedade com maior liberdade, justiça e eqüidade - não por pura teimosia, mas como um imperativo existencial e histórico do nosso tempo (GADOTTI, 1996b, p. 664).

Ampliando a amorosidade patente já na "Pedagogia do oprimido", bem como nas outras obras, a "Pedagogia da esperança" surge profundamente ligada aos afetos e à perspectiva crítica face à realidade vivida:

A Pedagogia da esperança: um reencontro com a pedagogia do oprimido é um livro assim, escrito com raiva, com amor, sem o que não há esperança. Uma defesa da tolerância, que não se confunde com a conivência, da radicalidade; uma crítica ao sectarismo, uma compreensão da pós-modernidade progressista e uma recusa à conservadora, neoliberal (FREIRE, 1994, p. 12).

Trata-se de uma obra enraizada no seu tempo que busca uma linguagem de recuperação de uma realidade esperançosa, e de coerência entre "dito" e "feito". Nela, Freire assume que procura "re-tomar" de forma transformadora a "Pedagogia do oprimido" "na sua 'maioridade', para re-ver, re-pensar, para re-dizer" (FREIRE, 1994, p. 53). Nesse enquadramento, reconhecendo que a desesperança alimenta o fatalismo e a falta de força mobilizadora, reconhece também e afirma a necessidade da esperança como catalisador para a vocação ontológica para ser mais, como seres transformadores do mundo. A não realização dessa vocação constituirá, como lembra, uma "distorção da história". Assim proclama, "não sou esperançoso por pura teimosia mas por imperativo existencial e histórico" (FREIRE, 1994, p. 10).

A "Pedagogia da esperança" parece vir em cumprimento desse imperativo, porque se constrói em processos de reflexão acerca do que foi e do que está sendo a "Pedagogia do oprimido", já então lida e traduzida por todo o mundo. De forma pertinente para este artigo que busca a "Pedagogia do oprimido" no interior da "Pedagogia da esperança", Romão (2008, p. 9) considera estas duas obras, a par da "Pedagogia da autonomia" como o cerne da obra de Freire, acentuando a preocupação deste com "a criação, a escritura e a publicação de

\begin{tabular}{l|c|c|c|c|c|c} 
() Rev. Educ. Perspec. & Viçosa, $M G$ & v.9 & n.3 & p.564-575 & set./dez. 2018 & eISSN 2178-8359 \\
\hline
\end{tabular}


"pedagogias"”. O termo "pedagogia" emerge configurado na argumentação do autor como "processo civilizatório", justificando, como afirma, a:

recomendação de Paulo Freire em se estabelecer a pedagogia como uma práxis (reflexão e ação) preferencial deste início de século. [...] Enquanto prática e ciência [...] enquanto ação e organização da reflexão sistemática sobre esta ação, enquanto práxis, enfim, a pedagogia permite a atualização das potencialidades humanas (ROMÃO, 2008, p. 14).

É em oposição à ideologia dominante que desvaloriza sonho e utopia, e que constitui bloqueio a um processo civilizatório humanizado e humanizante, que Freire, na sua "filosofia política da educação" (MACEDO et al., 2013) afirma o seu papel, nem sempre reconhecido, como político e educador. Assume também a dimensão de resistência da prática educativa política, de reflexão e de ação, construtora de sonhos. Ao reclamar o papel de desocultação dos mitos dominantes, essa práxis permite também a construção de novos mundos possíveis, instalando e legitimando formas "outras" de pensamento-linguagem:

\begin{abstract}
Quando muita gente faz discursos pragmáticos e defende nossa adaptação aos fatos, acusando sonho e utopia não apenas de inúteis, mas também de inoportunos enquanto elementos que fazem necessariamente parte de toda prática educativa desocultadora das mentiras dominantes, pode parecer estranho que eu escreva um livro chamado Pedagogia da esperança: um reencontro com a pedagogia do oprimido. Para mim, pelo contrário, a prática educativa de opção progressista jamais deixará de ser uma aventura desveladora, uma experiência de desocultação da verdade. É porque sempre pensei assim que, às vezes, se discute se sou ou não um educador (FREIRE, 1994, p. 9).
\end{abstract}

$\mathrm{Na}$ "Pedagogia da esperança", Freire continua a argumentar em favor do radicalismo crítico e a afirmar-se contra os sectarismos. Mantém a perspectiva de esperança que orientou a escrita da "Pedagogia do oprimido", trazendo agora à evidência a força do sonho para uma práxis libertadora. Esta força é afirmada em excertos, que capturam a tese crucial de toda a sua abordagem, como "Sem sonhos não há futuro diferente, não havendo futuro novo, a educação torna-se adestramento" (FREIRE, 1994, p. 92) e "o sonho é assim uma exigência ou uma condição que se vem fazendo permanente na história que fazemos e que nos faz e re-faz" (FREIRE, 1994, p. 99).

Não sendo a palavra "sonho" referida na "Pedagogia do oprimido", a linguagem do sonho surge com frequência na "Pedagogia da esperança", enraizando a visão, já anunciada, da história como possibilidade. Aí, Freire enuncia o papel de homens e mulheres como construtores da história, sendo a ação humana catalisada pelo sonho, como condição para a mudança e condicionado pela esperança. É o sonho que torna a história inteligível e realizável, permitindo ir além de concepções "deterministas", alimentadas pelos grupos dominantes. É nesta medida que, como diz Freire, "Sonhar não é apenas um ato político necessário, mas também uma conotação da forma histórico-social de estar sendo de mulheres e homens" (FREIRE, 1994, p. 91). Evidencia-se o encorajamento ao processo de libertação e

\begin{tabular}{l|c|c|c|c|c|c} 
(C) Rev. Educ. Perspec. & Viçosa, $M G$ & v.9 & n.3 & p.564-575 & set./dez. 2018 & eISSN 2178-8359 \\
\hline
\end{tabular}


emancipação, e uma filosofia política de educação que a constitui como forma de intervenção no mundo que dá resposta a essas finalidades, ou seja, uma pedagogia que recupera a esperança, a qual, por sua vez, constitui um elo entre os sonhos e a realidade:

\begin{abstract}
Por isso, venho insistindo, desde a Pedagogia do oprimido, que não há utopia verdadeira fora da tensão entre a denúncia de um presente tornando-se cada vez mais intolerável e o anúncio de um futuro a ser criado, construído, política, estética e eticamente, por nós, mulheres e homens. [...] A nova experiência de sonho se instaura, na medida mesma em que a história não se imobiliza, não morre. Pelo contrário, continua (FREIRE, 1994, p. 91-92).
\end{abstract}

Assente na denúncia e no anúncio de outro mundo possível, a aprendizagem política do compromisso com a utopia, permite ultrapassar os discursos pragmáticos do "sempre foi assim", fornecendo instrumentos aos grupos dominados para a emergência do sonho sonhado e da luta para a transformação social. Esta é alimentada pelo sonho como necessidade humana:

\begin{abstract}
Homens e mulheres, ao longo da história [...] inventamos a possibilidade de nos libertar na medida em que nos tornamos capazes de nos perceber como seres inconclusos, limitados, condicionados, históricos. Percebendo, sobretudo, também, que a pura percepção da inconclusão, da limitação, da possibilidade, não basta. É preciso juntar a ela a luta política pela transformação do mundo. A libertação dos indivíduos só ganha profunda significação quando se alcança a transformação da sociedade. O sonho se faz uma necessidade, uma precisão (FREIRE, 1994, p. 100).
\end{abstract}

Torna-se também relevante acentuar a amplificação do conceito de "luta", no texto sobre as tensões sociais entre diferentes grupos, que Freire apresenta na Pedagogia da esperança como "categoria histórica" assumindo a sua historicidade e mudança no espaço-tempo. Sendo evidenciadas as lutas de classe, o conceito de classe social é também aqui complexificado, não se perdendo de vista a partilha de interesses de classe, as lutas de classe e a necessidade de diálogo entre elas. Assim, face à incorporação de críticas ao seu trabalho, e à incorporação de novos textos teóricos e experienciais, Freire acentua que a "luta de classes não é o motor da história mas certamente é um deles" (FREIRE, 1994, p. 91, grifo do original). Pode assim afirmar-se que:

\footnotetext{
o trabalho de Freire se enquadra e corporiza um movimento de desafio ao modelo de neutralidade aparente da educação, para debater o poder em termos das classes sociais, e [...] outras dimensões, como o género [...]. Esta enunciação é particularmente premente nos tempos que correm, justificando a sua pertinência, hoje e no futuro (MACEDO; CARVALHO, 2017, p. 35).
}

O olhar interpretativo aos textos permite a identificação de um conjunto de linhas comuns destacando-se a posição explícita ao lado dos oprimidos, conceito cuja complexidade é reforçada na Pedagogia da esperança, em que Freire tem mais em conta as questões de gênero, de etnia e outras, como estruturas de discriminação. A "Pedagogia da esperança" reafirma a crença no ser humano oprimido, ampliando o conceito às maiorias humilhadas, marginalizadas, exploradas, excluídas, em múltiplas identidades: o trabalhador explorado, o

\begin{tabular}{l|l|l|l|l|l|l} 
(C) Rev. Educ. Perspec. & Viçosa, $M G$ & v.9 & n.3 & p.564-575 & set./dez. 2018 & eISSN 2178-8359 \\
\hline
\end{tabular}


camponês, o negro, o índio, o mestiço, a mulher, o portador de deficiência ou de qualquer marca de discriminação. Ultrapassa-se assim a perspectiva mais polarizada da "Pedagogia do oprimido", que se articula com a influência marxista, em que o funcionamento social residia na dualidade entre uma minoria - a classe dominante/opressora - determinada no seu poder incessante de exploração da vida e da força de trabalho da classe dominada, e do outro lado os oprimidos. Evidencia-se a opção ética e humanística de luta contra a opressão de indivíduos e grupos, e em favor da vida e da liberdade.

\section{LINHAS CONCLUSIVAS}

O reencontro com a "Pedagogia do oprimido" na "Pedagogia da esperança" é evidenciado pela atualização, reafirmação e revisão por Freire, das suas reflexões. Ao esclarecer a produção da "Pedagogia do oprimido", a "Pedagogia da esperança" expõe e aprofunda a análise aí apresentada, num reconto/reencontro com situações marcantes da vida de Freire, em termos da trajetória de escrita, alimentada pelo sonho e em busca de libertação. Destas situações fazem parte a publicação e diálogos, com diversas populações e em diversos países, acerca da sua pedagogia crítica e libertadora. Assim, a "Pedagogia da esperança" aprofunda e argumenta em favor daquilo que designamos por uma intertextualidade coerente na díade vida-obra.

Na linha de outros trabalhos, a "Pedagogia da esperança" a par da "Pedagogia do oprimido" permite identificar contributos fundamentais para a reflexão sobre as opções políticas, históricas e pedagógicas que mobilizam o trabalho educativo. Obrigando a um questionamento crítico acerca do nosso posicionamento político e gnosiológico face à libertação "dos oprimidos e esfarrapados do mundo", estas obras permitem repensar as características das nossas práticas educativas, no binômio entre uma prática libertadora e progressista, e uma prática bancária desumanizadora e reprodutora do status quo. Conduzem para além disso à reflexão acerca das premissas orientadoras da nossa atuação no mundo, e dos contributos da nossa ação para a libertação de oprimidos e opressores, como conceitos que requerem forte complexificação no espaço-tempo. A reclamação da unidade na diversidade, do diálogo, do respeito pelo saber e pela linguagem, a problematização e o amor como condições para uma práxis libertadora reforçam-se também na "Pedagogia da esperança", a par de um conjunto de questões que não foi possível explorar no âmbito deste trabalho. 


\section{REFERÊNCIAS}

ABRAMOWICZ, Mere. Amor e perda em tempos de vida: em dois momentos entrelaçados. In: GADOTTI, Moacir (Org.). Paulo Freire: uma biobibliografia. São Paulo: Paz e Terra, UNESCO, IPF, 1996. P. 201-203.

CORTESÃO, Luiza. Contributo para a compreensão do trabalho de Paulo Freire. Fênix: Revista Pernambucana de Educação Popular e Educação de Adultos, v. 2, n. 1, p. 26-34, 2003.

FREIRE, Ana. Paulo Freire: pedagogia dos sonhos possíveis. São Paulo: UNESP, 2001.

FREIRE, Paulo. Pedagogia da esperança: um reencontro com a pedagogia do oprimido. Rio de Janeiro: Paz e Terra, 1994.

FREIRE, Paulo. Pedagogia do oprimido. 29 ed. Rio de Janeiro: Paz e Terra, 2000.

GADOTTI, Moacir (Org.). Paulo Freire: uma biobibliografia. São Paulo: Cortez Editora, 1996a.

GADOTTI, Moacir. A esperança como imperativo existencial e histórico. In: GADOTTI, Moacir (Org.). Paulo Freire: uma biobibliografia. São Paulo: Cortez Editora, 1996b. P. 661664.

GADOTTI, Moacir. Convite à leitura de Paulo Freire. São Paulo: Scipione, 2001.

GUERRERO, Miguel Escobar. Las quatro etapas de Paulo Freire en sus cinco pedagogías: del oprimido, de la esperanza, de la autonomía, de la indignación y de la tolerância. In: VELAZCO, Juan Carlos Yañez (Coord.). Paulo Freire: praxis de la utopía y la esperanza. Colima: Universidad de Colima, 2007. P. 25-54.

GUTIÉRREZ, Francisco. A dimensão humana em Paulo Freire. In: TORRES, Carlos Alberto et al. Reinventando Paulo Freire no Século 21. São Paulo: IPF, 2008. P. 57-62.

MACEDO, Eunice. Ecos de Freire e o pensamento feminista: diálogos e esclarecimentos. Porto: LivPsic, IPFP, CRPF, CIIE, 2017.

MACEDO, Eunice; CARVALHO, Alexandra. Um diálogo epistemológico com Freire: palavra, práxis e educação. e-Mosaicos, v. 6, n. 13, p. 26-37, dez. 2017.

MACEDO, Eunice et al. Revisitando Paulo Freire: sentidos na educação. Brasília: Liber Livro, 2013.

MOI, Toril. Simone de Beauvoir: conflits d'une intellectuelle. Paris: Diderot Editeur, Arts et Science, 1995.

\begin{tabular}{|c|c|c|c|c|c|c|}
\hline (C) Rev. Educ. Perspec. & Viçosa, $M G$ & v.9 & n. 3 & p.564-575 & set./dez. 2018 & eISSN 2178-8359 \\
\hline
\end{tabular}


ROMÃO, José Eustáquio. Dialética da diferença: O projeto da escola cidadã frente ao projeto pedagógico neoliberal. São Paulo: Cortez, 2000.

ROMÃO, José Eustáquio. Pedagogias de Paulo Freire. Revista Múltiplas Leituras, v. 1, n. 2, p. 8-22, jul./dez. 2008.

SOUZA, Ana Inês. Paulo Freire: vida e obra. São Paulo: Expressão Popular, 2001.

TORRES, Carlos Alberto. Pedagogia da luta: da pedagogia do oprimido à escola pública popular. Campinas: Papirus, 1997.

\section{NOTAS}

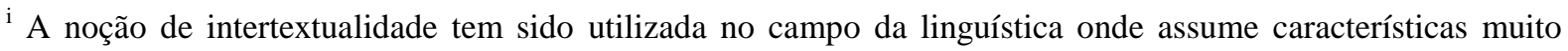
particulares. Não é nesse debate que investe este artigo.

${ }^{\text {ii }}$ Excertos da dedicatória a Freire, na obra "Dialética da Diferença" (2000).

iii Para além disso, gostaríamos de acentuar que Simone de Beauvoir é uma das poucas intelectuais femininas (e/ou feministas) formalmente reconhecidas por Freire, através da referência ao seu pensamento, a par de autoras como Hannah Arendt e Ágnes Heller.

iv Tradução livre.

v A única mulher até aos nossos dias a desempenhar a função de primeiro-ministro em Portugal, entre julho de 1979 e janeiro de 1980 .
}

\section{Sobre as autoras}

Eunice Macedo - Professora Auxiliar na Faculdade de Psicologia e de Ciências da Educação da Universidade do Porto. Investigadora do Centro de Investigação e Intervenção Educativas FPCEUP. E-mail: eunice@fpce.up.pt - ORCID: http://orcid.org/0000-0003-1200-6621

Alexandra Carvalho - Formação em Serviço Social na área da imigração e direitos humanos. Instituto Paulo Freire de Portugal. CIIE-FPCEUP. E-mail: alex_carvalho@fpce.up.pt - ORCID: http://orcid.org/0000-0003-0375-1873 